\title{
Production of 1,3-PDO and butanol by a mutant strain of Clostridium pasteurianum with increased tolerance towards crude glycerol
}

\author{
Torbjørn ØIshøj Jensen ${ }^{1}$, Thomas Kvist ${ }^{2}$, Marie Just Mikkelsen ${ }^{2}$ and Peter Westermann ${ }^{1 *}$
}

\begin{abstract}
The production of biodiesel results in a concomitant production of crude glycerol (10\% w/w). Clostridium pasteurianum can utilize glycerol as sole carbon source and converts it into 1,3-propanediol, ethanol, butanol, and $\mathrm{CO}_{2}$. Reduced growth and productivities on crude glycerol as compared to technical grade glycerol have previously been observed. In this study, we applied random mutagenesis mediated by ethane methyl sulfonate (EMS) to develop a mutant strain of $C$. pasteurianum tolerating high concentrations of crude glycerol. At an initial crude glycerol concentration of $25 \mathrm{~g} / \mathrm{l}$ the amount of dry cell mass produced by the mutant strain was six times higher than the amount produced by the wild type. Growth of the mutant strain was even detected at an initial crude glycerol concentration of $105 \mathrm{~g} / \mathrm{l}$. A pH controlled reactor with in situ removal of butanol by gas-stripping was used to evaluate the performance of the mutant strain. Utilizing stored crude glycerol, the mutant strain showed significantly increased rates compared to the wild type. A maximum glycerol utilization rate of $7.59 \mathrm{~g} / \mathrm{l} / \mathrm{h}$ was observed along with productivities of $1.80 \mathrm{~g} / / / \mathrm{h}$ and $1.21 \mathrm{~g} / / / \mathrm{h}$ of butanol and 1,3-PDO, respectively. These rates are higher than what previously has been published for C. pasteurianum growing on technical grade glycerol in fed batch reactors. In addition, high yields of the main products (butanol and 1,3-PDO) were detected and these two products were efficiently separated in two steams using gas-stripping.
\end{abstract}

Keywords: Glycerol, Crude glycerol, Biofuel, Anaerobic fermentation, Chemical mutagenesis

\section{Introduction}

Limited availability of fossil resources and increasing global impact from the release of fossil fuel-derived $\mathrm{CO}_{2}$ has increased the development of biological production of renewable alternatives. Biodiesel production from plant lipids is considered a renewable alternative to mineral oil-derived diesel (Demirbas 2007). The increasing market for biodiesel has substantially altered the cost and availability of glycerol released from transesterification of fatty acids from lipids. Without purification, this glycerol (crude glycerol), is considered a waste (Johnson and Taconi 2007; Dobson et al. 2012) and it is, therefore, important that new and sustainable solutions for utilization of the crude glycerol are developed (Pyle et al.

\footnotetext{
* Correspondence: pw@bio.aau.dk

'Section for Sustainable Biotechnology, Aalborg University, Copenhagen, A.C. Meyers Vaenge 15, DK-2450 Copenhagen SV, Denmark

Full list of author information is available at the end of the article
}

2008; Yazdani and Gonzalez 2007; Willke and Vorlop 2008).

The major microbial conversion route of glycerol leads to the production of 1,3-propanediol (1,3-PDO) (Pagliaro et al. 2007). Currently, 1,3-PDO is used as a diol component in the plastic poly-trimethylene terephthalate (PTT), which is comparable to nylon (Willke and Vorlop 2008). PTT is mainly used for carpet and textile fiber production (DuPont ${ }^{\mathrm{m}}{ }^{\mathrm{S}}$ Sorona ${ }^{\circledR}$ 2011). The organisms best known for producing 1,3-PDO are Clostridium butyricum and Klebsiella pneumoniae, which both can achieve high yields and productivities (Biebl et al. 1999; Zeng et al. 1994).

Since the 1,3-PDO pathway does not lead to ATP production, other pathways are needed for the generation of energy. The formation of acetate and/or butyrate leads to ATP production but is also associated with the generation of reducing equivalents, which are regenerated by the 1,3-PDO pathway (Rossi et al. 2012; Zeng 1996). 
The most commonly used strategy for 1,3-PDO production is fed-batch fermentation, because it combines high product concentrations with a low excess of glycerol in the fermentation broth, which both are critical for the downstream processing (Zeng and Biebl 2002). However, accumulation of by-products such as acetate, butyrate, or ethanol can cause inhibition of the organism (Biebl 1991).

Butanol is an important bulk chemical for the synthesis of a variety of chemical products and an efficient biofuel with properties clearly superior to ethanol such as lower enthalpy of vaporization, lower solubility of water, less corrosiveness, and a much higher energy density (Dürre 2008).

The production of butanol and 1,3-PDO from biodiesel derived glycerol will not only constitute a sustainable utilization of waste glycerol for fuel production, but also a means to produce two chemicals, which can be used in the chemical industry.

The most studied organism for biological production of butanol is C. acetobutylicum. However, C. acetobutylicum cannot grow solely on glycerol as it cannot re-oxidize the excess NADH generated in the cellular glycerol catabolism. (Girbal et al. 1995; Gonzalez-Pajuelo et al. 2005)

In contrast to $C$. butyricum which produces $1,3-\mathrm{PDO}$ along with the formation of butyrate and acetate, $C$. pasteurianum produces butanol, 1,3-PDO, and ethanol as main products. Fermentation of glycerol by C. pasteurianum was firstly described by Nakas et al. (1983) in an attempt to obtain a marketable product from photosynthetically produced glycerol from halophilic algae.

Only few publications have dealt with optimization of glycerol fermentation by C. pasteurianum (Biebl 2001; Dabrock et al. 1992). Recently, a study demonstrating the possibility of utilizing crude glycerol in fermentative butanol production has been published (Taconi et al. 2009). However, growth and productivity were significantly lower compared to results obtained from fermentation of pure glycerol. In order to achieve a high productivity, upstream purification has been successfully applied (Venkataramanan et al. 2012; Jensen et al. 2012). Another approach is to develop strains capable of coping with the toxicity of the crude glycerol. To construct/ develop such an organism a directed or a random approach can be used. Even though directed strain improvement by systems metabolic engineering may be necessary as reported by (Lee et al. 2005) and Lee et al. (2008) the lack of a complete genome sequence and adequate tools limits the application on C. pasteurianum.

In this study we have, therefore, chosen to develop a strain of $C$. pasteurianum with elevated tolerance towards to crude glycerol derived from the biodiesel production by use of chemical mutagenesis and selection.

\section{Materials and methods Bacterial strain}

The strain C. pasteurianum (DMSZ 525) was purchased from the German Collection of Microorganism and Cell Cultures (DSMZ), Göttingen, Germany.

\section{Medium and conditions}

The minimal medium used for both reactor and $10 \mathrm{ml}$ batch fermentations was described by Jensen et al. (2012). When solid media were used, $15 \mathrm{~g} / \mathrm{l}$ agar was added to the media prior to autoclavation. All cultures were incubated anaerobically at $37^{\circ} \mathrm{C}$ at $\mathrm{pH} 6.0$ under a gas phase of $\mathrm{N}_{2} / \mathrm{CO}_{2}$ (80:20). The carbon source was either purified (technical grade) glycerol (Sigma-Aldrich, St. Louis, Missouri, USA) or biodiesel derived crude glycerol (Meroco, Leopoldov, Slovakia). The crude glycerol was derived from 100\% rape seed oil and was specified to contain $800-850 \mathrm{~g} / \mathrm{l}$ glycerol, less than $1 \mathrm{~g} / \mathrm{l}$ methanol, $55 \mathrm{~g} / \mathrm{l} \mathrm{NaCl}$ and 2.5\% MONG (matter organic non glycerol) by the manufacturer. All amounts of crude glycerol presented are based on measured concentrations.

\section{Chemical mutagenesis and evolutionary adaption}

A fresh C. pasteurianum culture $(50$ or $100 \mu \mathrm{L})$ was plated on petri dishes containing solid minimal medium supplemented with $50 \mathrm{~g} / \mathrm{l}$ and $70 \mathrm{~g} / \mathrm{l}$ crude glycerol. A drop (approximately $7 \mu \mathrm{l}$ ) of ethane methyl sulfonate (EMS) was placed in the middle of the plates. The plates were incubated at $37^{\circ} \mathrm{C}$ for three days in an anaerobic jar together with a humid anaerocult ${ }^{\circledR}$ A (Merck, Darmstadt, Germany). An inoculated plate (without EMS) was incubated as a control in the jar.

After incubation, single colonies were picked from the edge of the clearing zones caused by EMS. The selected colonies were streaked on plates with similar or higher glycerol concentration without EMS. When growth was detected, the colonies were repeatedly streaked on plates with similar or higher glycerol concentration to increase the tolerance towards the crude glycerol. The crude glycerol concentration in the medium was; $50,60,70,80$, 90, 100 , and $110 \mathrm{~g} / \mathrm{l}$.

Colonies able to grow on $110 \mathrm{~g} / \mathrm{l}$ crude glycerol plates were inoculated in liquid minimal medium supplemented with $25 \mathrm{~g} / \mathrm{l}$ crude glycerol. The liquid culture was used as inoculums for the toxicity test.

\section{Treatment of the crude glycerol}

Glycerol was stored at room temperature for 10 months as previously described (Jensen et al. 2012. Approximately $0.05 \mathrm{~g}$ of activated stone carbon $0.4-0.85 \mathrm{~mm}$ per $10 \mathrm{ml}$ of medium (Gert Strand, Malmö, Sweden) was added prior to autoclavation (Jensen et al. 2012). 


\section{Toxicity test}

To assess the inhibition of the glycerol, toxicity tests were performed in batch experiments. A series of vials were prepared with different concentrations of glycerol ranging from 10 to $200 \mathrm{~g} / \mathrm{l}$. The vials were inoculated with $0.2 \mathrm{ml}$ of an overnight culture. After 20 hours of incubation, growth was evaluated based upon the amount of dry cell mass. The dry cell mass was determined spectrophotometrically after establishing a linear correlation between the dry cell mass and cell suspension absorbance at $595 \mathrm{~nm}$. All tests were conducted in at least duplicates.

\section{Reactor fermentation}

The reactor fermentation experiments were carried out as described by Jensen et al. (2012) in $500 \mathrm{ml}$ glass reactors at $37^{\circ} \mathrm{C}$. The active volume was $400 \mathrm{ml}$ and the inoculation volume was $10 \% \mathrm{pH}$ was maintained at 6.0 by addition of $1 \mathrm{M} \mathrm{KOH}$. Mixing was performed by magnetic stirring. For in situ removal of solvent, gasstripping was applied, circulating the produced gas by means of a peristaltic pump at a flow rate of approximately $600 \mathrm{ml} / \mathrm{min}$.

For stoichiometric calculations the composition of cell biomass was assumed to be $\mathrm{CH}_{1.65} \mathrm{~N}_{0.23} \mathrm{O}_{0.45}$ (Hild et al. 2003).

\section{HPLC analysis}

Liquid samples were analyzed for glycerol, lactate, acetate, 1,3-PDO, butyrate, ethanol, acetone, and butanol using high-pressure liquid chromatography. The HPLC system was equipped with a Rezex ROA-Organic Acid column (Phenomenex, Torrance, California, USA) and a RI 101 refractive index detector (Shodex, Kawasaki, Japan). The mobile phase was $4.5 \mathrm{mM} \mathrm{H}_{2} \mathrm{SO}_{4}$, pumped at a flow-rate of $0.6 \mathrm{~mL} / \mathrm{min}$. Prior to the analysis the samples were centrifuged at $12,000 \mathrm{x}$ g for 10 minutes. The supernatant was separated and diluted to a suitable concentration range before it was loaded on the HPLC.

\section{Results}

\section{Strain development}

After incubation in the presence of EMS for 3 days, colonies appeared only on the plates with the lowest initial crude glycerol concentration (50 g/l). A clearing zone was present on the plates around the droplet of EMS. In total, 37 colonies from the edge of the clearing zone were picked and streaked on plates with $50 \mathrm{~g} / \mathrm{l}$ glycerol serving as a strain library. Repeated transfers of the colonies to plates with increasingly higher glycerol concentrations enhanced the tolerance to the crude glycerol further. However, only few of the 37 colonies were able to grow at a crude glycerol concentration of $110 \mathrm{~g} / \mathrm{l}$. The most promising four strains were benchmarked in a toxicity test towards the wild type strain (Figure 1). At an

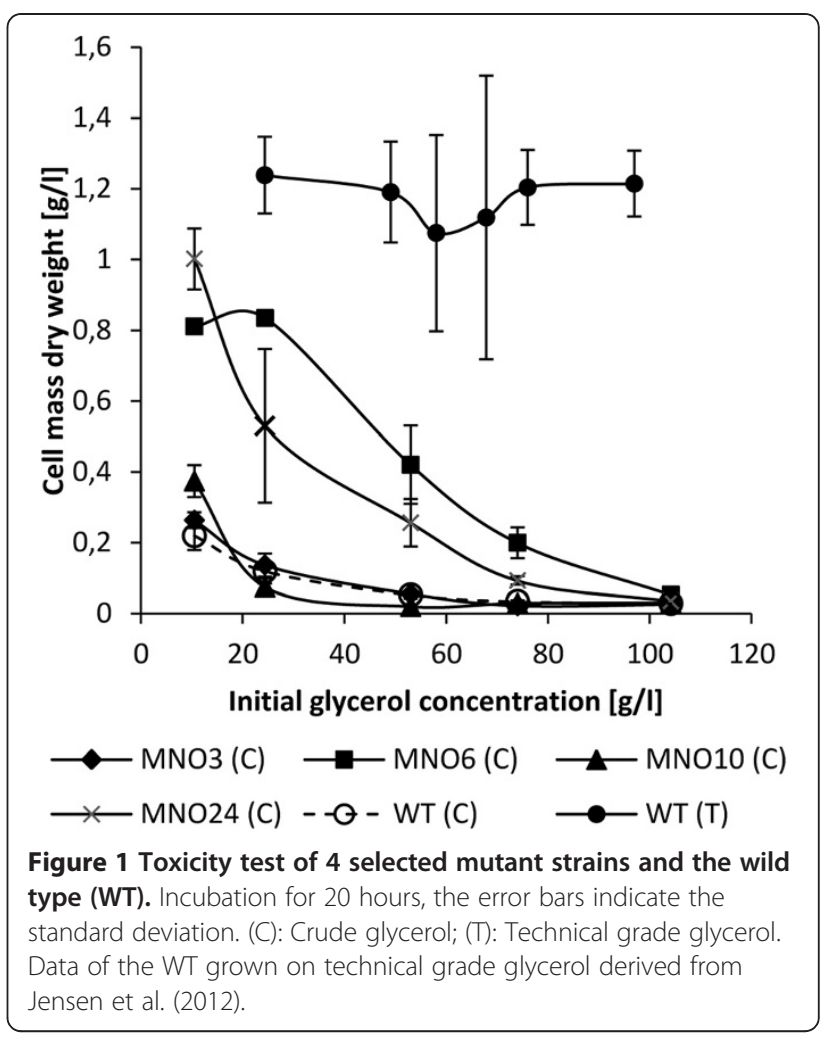

initial glycerol concentration of $25 \mathrm{~g} / \mathrm{l}$ the amount of dry cell mass of MNO24 was 3.5 times higher compared to the wild type on crude glycerol, however, with a considerable deviation. At the same initial glycerol concentration, MNO6 grew better than the wild type, producing 6 times the amount of dry cell mass. Growth characteristics by the mutant strains MNO3 and MNO10 were almost similar to the wild type. At an initial crude glycerol concentration of $53 \mathrm{~g} / \mathrm{l}$ growth by the wild type, MNO3, and MNO10 was almost negligible, while MNO6 and MNO24 were less inhibited than the wild type grown on technical grade glycerol. At an initial glycerol concentration of $75 \mathrm{~g} / \mathrm{l}$, MNO6 produced $16.5 \%$ dry cell mass compared to the wild type growing on technical grade glycerol. The amount of dry cell mass produced by MNO24 constituted $7.7 \%$ of the amount produced by the wild type on technical grade glycerol while the wild type on crude glycerol only yielded $2 \%$. At an initial glycerol concentration of $105 \mathrm{~g} / \mathrm{l}$, growth of MNO6 was detectable. Based on these results strain MNO6 appeared most tolerant to crude glycerol and was, therefore, chosen for the subsequent experiments.

Chemical mutagenesis selecting for increased tolerance may lead to down-regulation of the genes responsible for the desired products (Borden and Papoutsakis 2007). Therefore, the product concentration at different initial glycerol concentrations was measured (Figure 2). Strain MNO6 exhibited the highest growth and achieved the 


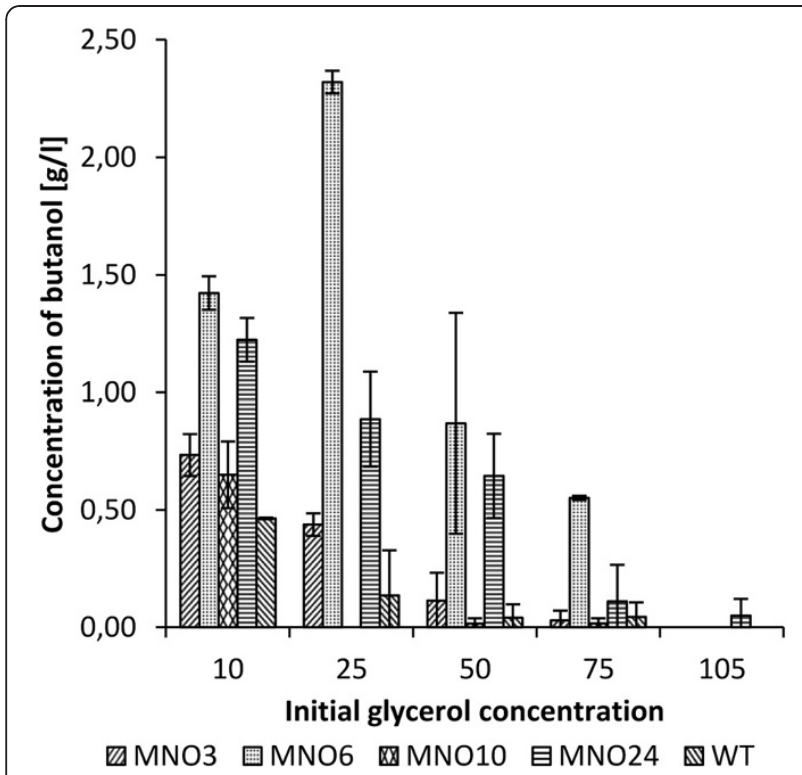

Figure 2 Histogram showing the concentration of butanol at different initial crude glycerol concentrations after 20 hours of incubation. The error bars indicate the standard deviation.

highest concentration of butanol. At $25 \mathrm{~g} / \mathrm{l}$, strain MNO6 produced $2.32 \mathrm{~g} / \mathrm{l}$ butanol while the wild type only produced $0.14 \mathrm{~g} / \mathrm{l}$. This demonstrates that the enhanced tolerance by MNO6 was neither achieved at the expense of butanol formation nor by product degradation.

We have previously found that growth on crude glycerol was highly supported by storage of the glycerol combined with supplementation of activated stone carbon (Jensen et al. 2012). To assess growth at these conditions, strain MNO6 was benchmarked against the wild type in a toxicity test (Figure 3). As expected, the amount of dry cell mass produced by both strains on treated crude glycerol was higher compared to the amount produced on nontreated crude glycerol, and even higher than the amount produced by the wild type on technical grade glycerol (Figure 1). Compared to the wild type, MNO6 was less inhibited by the treated crude glycerol, as more cell mass was produced. However, the difference between the strains was only significant at $25 \mathrm{~g} / \mathrm{l}(\mathrm{p}=0.047)$.

\section{Fermentation}

To assess the fermentation capabilities of MNO6 under $\mathrm{pH}$ controlled conditions, a reactor fermentation was set up utilizing stored crude glycerol supplemented with activated stone carbon. MNO6 was not tested on technical grade glycerol as it was irrelevant for industrial applications. The fermentation profile is shown in Figure 4. During the initial 21 hours, only a slow glycerol consumption was observed. After 21 hours the consumption of glycerol increased until a maximum rate of $7.59 \mathrm{~g} / \mathrm{l} / \mathrm{h}$ was reached after 39 hours of

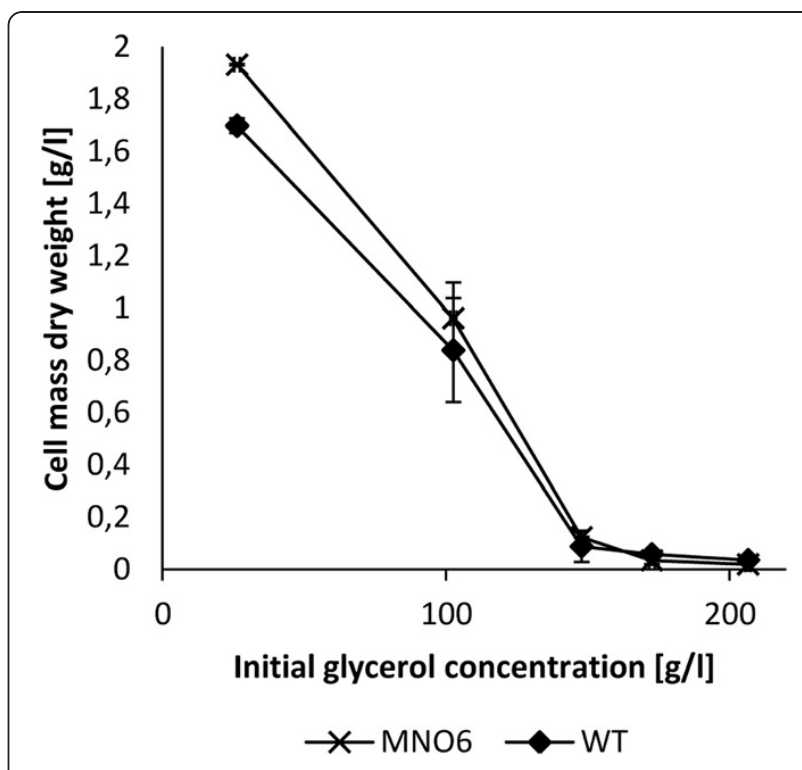

Figure 3 Toxicity test of strain MNO6 and the wild type grown on stored crude glycerol supplemented with activated stone carbon. Incubation for 20 hours, the error bars indicate the standard deviation.

incubation. In order to maintain a sufficient amount of substrate, $25 \mathrm{ml}$ glycerol $(250 \mathrm{~g} / \mathrm{l})$ was added shortly after the maximum rate had been achieved. After this, too high amounts of butanol were produced and the gas stripper could no longer maintain the concentration below the toxic level. After 43.75 hours butanol concentration reached $12.6 \mathrm{~g} / \mathrm{l}$ which arrested the metabolism of MNO6. When no production occurred, the removal rate by the gas-stripper was estimated to $0.79 \mathrm{~g} / \mathrm{l} / \mathrm{h}$ at the observed butanol concentration. Accounting for butanol removal, the maximum butanol productivity was calculated to $1.80 \mathrm{~g} / \mathrm{l} / \mathrm{h}$. In the same period 1,3-PDO productivity was $1.21 \mathrm{~g} / \mathrm{l} / \mathrm{h}$. Although, no butanol was produced for a considerable period, it was not possible to reduce butanol concentration below $5 \mathrm{~g} / \mathrm{l}$ with this reactor-setup. After 75 hours, gas circulation was stopped and the products were quantified. Since, the activity was unaffected by addition of glycerol at $t=39.25 \mathrm{~h}$ and the activity did not resume when the butanol concentration was reduced below $6 \mathrm{~g} / \mathrm{l}$, at which the wild type regain metabolic activity (Jensen et al. 2012), a lack of nutrients have probably caused the discontinuation.

A mass-balance in mol based on the measured products was established:

$$
\begin{aligned}
\mathrm{C}_{3} \mathrm{H}_{8} \mathrm{O}_{3} & \rightarrow 0.251 \mathrm{C}_{3} \mathrm{H}_{8} \mathrm{O}_{2}+0.036 \mathrm{C}_{2} \mathrm{H}_{4} \mathrm{O}_{2} \\
& +0.018 \mathrm{C}_{2} \mathrm{H}_{6} \mathrm{O}+0.020 \mathrm{C}_{4} \mathrm{H}_{8} \mathrm{O}_{2} \\
& +0.252 \mathrm{C}_{4} \mathrm{H}_{10} \mathrm{O}+0.559 \mathrm{CO}_{2} \\
& +0.388 \mathrm{H}_{2}+0.466 \mathrm{H}_{2} \mathrm{O} \\
& +0.184 \text { cell-biomass }
\end{aligned}
$$




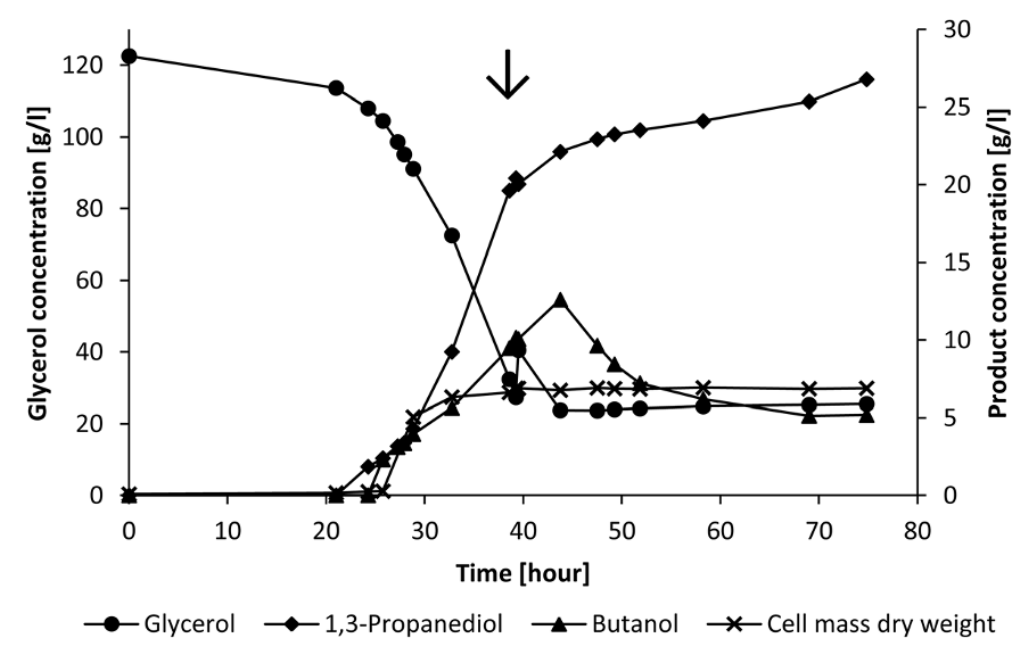

Figure 4 Profile of the fermentation of stored crude glycerol supplemented with activated stone carbon by MNO6. The initial glycerol concentration was $122 \mathrm{~g} / \mathrm{l}$, pH was maintained at 6 , and the temperature was $37^{\circ} \mathrm{C}$. Butanol concentration was measured in the fermentation broth. The arrow indicates the addition of $25 \mathrm{ml}$ glycerol $(250 \mathrm{~g} / \mathrm{l})$.

The strain did not produce any lactate, and only very low amounts of acetate, ethanol, and butyrate. The carbon recovery was only $87 \%$. The missing carbon could be butanol, as accumulation of butanol in the gas collection bag was observed. Adding the gas-phase products to the mass balance leads to a butanol yield of $0.296 \mathrm{~mol} / \mathrm{mol}$ and a $\mathrm{CO}_{2}$ yield of $0.687 \mathrm{~mol} / \mathrm{mol}$. The butanol yield achieved represents $59.2 \%$ of the theoretical maximum based on the stoichiometry:

$$
2 \mathrm{C}_{3} \mathrm{H}_{8} \mathrm{O}_{3} \rightarrow \mathrm{C}_{4} \mathrm{H}_{10} \mathrm{O}+2 \mathrm{CO}_{2}+2 \mathrm{H}_{2}+\mathrm{H}_{2} \mathrm{O}
$$

The two main compounds 1,3-PDO and butanol were produced in almost equimolar amounts with a $18 \%$ surplus of butanol after the mass-balance had been adjusted.

\section{Discussion}

Random mutagenesis is a generally an accepted and widely used approach for increasing tolerance of a bacterial strain towards an unknown inhibitor. EMS and Nmethyl-N-nitro-N-nitrosoguanidine (MNNG), which both act by direct mutagenesis inducing base substitutions or deletions, have been used with success in the closely related C. acetobutylicum (Annous and Blaschek 1991; Elkanouni et al. 1989). Recently, Malaviya et al. (2012) succeeded in developing an effective butanol producing mutant strain of $C$. pasteurianum by the use of MNNG. However, both Lemmel (1985) and Syed et al. (2008) obtained C. acetobutylicum mutants with higher tolerance and productivity using EMS and reported that MNNG was a less effective mutagenic compound. Our success with increased tolerance towards crude glycerol and increased butanol productivity by EMS mutagenesis confirmed the efficiency of EMS for development of $C$. pasteurianum mutants. As the mutant strain was developed by chemical mutagenesis it will not be classified as a Gene Modified Organism (GMO) reducing the operating costs and safety precautions necessary to run a GMO-based production.

We have previously examined yields and fermentation of stored crude glycerol supplemented with activated stone carbon by C. pasteurianum wild type (Jensen et al. 2012). The fermentations by MNO6, performed in this study was done with the same crude glycerol as substrate and under almost similar conditions, and benchmarking of MNO6 against data from the wild type strain study, is therefore relevant (Table 1).

The maximum glycerol utilization rate attained by MNO6 was $7.59 \mathrm{~g} / \mathrm{l} / \mathrm{h}$ whereas the wild type strain reached rates of $4.08 \mathrm{~g} / \mathrm{l} / \mathrm{h}$ and $4.94 \mathrm{~g} / \mathrm{l} / \mathrm{h}$ utilizing stored crude glycerol and technical grade glycerol, respectively. This corresponds to an increased rate of $86 \%$ and $55 \%$ compared to the wild type on crude and technical grade glycerol. The production rates were similarly increased by $33 \%$ for $1,3-\mathrm{PDO}$ and $46 \%$ for butanol compared to the wild type grown on technical grade glycerol. When the rates achieved with MNO6 were compared to rates of the wild type grown on similar glycerol, maximum $1,3-\mathrm{PDO}$ productivity was increased by $89 \%$ and maximum butanol productivity was increased by $49 \%$. Malaviya et al. (2012) demonstrated significantly increased production rates in a high cell density continuous bioreactor using a so-called hyper producing C. pasteurianum mutant strain. Under batch conditions the mutant strain had a $14 \%$ higher butanol productivity compared to the wild type. This is lower than the increase in productivity by MNO6 demonstrated in this study. 
Table 1 Comparison of fermentation data obtained in this study with a related study

\begin{tabular}{|c|c|c|c|}
\hline & $\begin{array}{l}\text { Technical grade glycerol } \\
\text { (Jensen et al. 2012) } \\
\end{array}$ & $\begin{array}{l}\text { Stored crude glycerol + activated } \\
\text { stone carbon (Jensen et al. 2012) }\end{array}$ & $\begin{array}{l}\text { Stored crude glycerol + activated } \\
\text { stone carbon }\end{array}$ \\
\hline & Wild type & Wild type & MNO6 \\
\hline Maximum Glycerol rate & $4.94 \mathrm{~g} / \mathrm{l} / \mathrm{h}$ & $4.08 \mathrm{~g} / \mathrm{l} / \mathrm{h}$ & $7.59 \mathrm{~g} / \mathrm{l} / \mathrm{h}$ \\
\hline Maximum 1,3-PDO rate & $0.64 \mathrm{~g} / / / \mathrm{h}$ & $0.91 \mathrm{~g} / / / \mathrm{h}$ & $1.21 \mathrm{~g} / / / \mathrm{h}$ \\
\hline Maximum Butanol rate & $1.21 \mathrm{~g} / \mathrm{l} / \mathrm{h}^{*}$ & $1.30 \mathrm{~g} / / / \mathrm{h}$ & $1.80 \mathrm{~g} / / / \mathrm{h}$ \\
\hline Butanol yield & $264 \mathrm{mmol} / \mathrm{mol}$ & $280 \mathrm{mmol} / \mathrm{mol}$ & $252 \mathrm{mmol} / \mathrm{mol}$ \\
\hline 1,3-PDO yield & $217 \mathrm{mmol} / \mathrm{mol}$ & $169 \mathrm{mmol} / \mathrm{mol}$ & $251 \mathrm{mmol} / \mathrm{mol}$ \\
\hline Ethanol yield & $164 \mathrm{mmol} / \mathrm{mol}$ & $55 \mathrm{mmol} / \mathrm{mol}$ & $18 \mathrm{mmol} / \mathrm{mol}$ \\
\hline Carbon Recovery & $97 \%$ & $88 \%$ & $87 \%$ \\
\hline
\end{tabular}

*The rate was based on a fermentation without gas-stripping.

In a glucose fed batch bioreactor with gas-stripping, Ezeji et al. (2004) achieved a maximum butanol productivity of $1.81 \mathrm{~g} / \mathrm{l} / \mathrm{h}$ ( $65 \%$ of total solvent productivity) utilizing the well known $\mathrm{ABE}$ producing strain $C$. beijerinckii BA101. This is similar to the maximum butanol productivity achieved by MNO6. However, Ezeji et al. reached the productivity by utilizing pure glucose where MNO6 utilized stored crude glycerol.

In the mass balance the carbon recovery was $87 \%$ (Table 1). A similar carbon recovery was observed in the fermentation by the wild type utilizing stored crude glycerol supplemented with activated stone carbon (Table 1). We assume that the resulting carbon was noncondensed butanol in the gas-phase. Also, activated stone carbon has been considered as an adsorbent for butanol in downstream processing (Qureshi et al. 2005; Groot and Luyben 1986). When fermentations were carried out without activated stone carbon (on technical grade glycerol) a higher carbon recovery was observed (Table 1).

After adjusting the mass balance, the yield of butanol from stored crude glycerol by MNO6 was $0.296 \mathrm{~mol} / \mathrm{mol}$ compared to $0.264 \mathrm{~mol} / \mathrm{mol}$ by the wild type utilizing technical grade glycerol. Venkataramanan et al. (2012) reported a butanol yield of $0.347 \mathrm{~mol} / \mathrm{mol}$ by $C$. pasteurianum utilizing purified crude glycerol and $0.322 \mathrm{~mol} /$ mol when technical grade glycerol was used. Both yields are higher than those achieved by MNO6 and the wild type. Low initial glycerol concentration, low utilization of glycerol as well as other dissimilarities in growth conditions in the two studies, could cause this difference.

Strain MNO6 had a 1,3-PDO yield of $0.249 \mathrm{~mol} / \mathrm{mol}$, which is $47 \%$ higher than the yield by the wild type $(0.169 \mathrm{~mol} / \mathrm{mol})$ grown on stored crude glycerol. Even though the 1,3-PDO yield was lower than the theoretical maximum of $0.720 \mathrm{~mol} / \mathrm{mol}$ (Zeng 1996) MNO6 has an interesting potential, as 1,3-PDO is produced simultaneously with butanol. Productivity of 1,3-PDO in fed batch has been reported to $0.9-3.0 \mathrm{~g} / \mathrm{l} / \mathrm{h}$ by the dedicated
1,3-PDO producer C. butyricum (Willke and Vorlop 2008; Chatzifragkou et al. 2011; Wilkens et al. 2012; Reimann and Biebl 1996). The achieved maximum 1,3PDO production rate of $1.21 \mathrm{~g} / \mathrm{l} / \mathrm{h}$ by MNO6 is comparable to $C$. butyricum.

MNO6 produced ethanol in very small amounts $(0.018 \mathrm{~mol} / \mathrm{mol})$. Compared to the fermentation by the wild type, the ethanol yield was reduced by $68 \%$ and $89 \%$ from stored crude glycerol and technical grade glycerol, respectively. The biomass yield of MNO6 was also significantly reduced, constituting only $90 \%$ of the wild type. The reduced amount of biomass diminishes the need for ATP. By extrapolating the ATP yield from the mass balances (both in this study and from Jensen et al. 2012 (data not shown)) it is clear that also the ATP yield is reduced by $10 \%$ in MNO6. The reduced ATP requirement/production may be causing the shift in product pattern, as observed in this study.

In a fed-batch fermentation with MNO6 and in situ removal of butanol, 1,3-PDO would accumulate in the reactor, reaching high titers critical for downstream processing. Recently, the discovery of a bacterial strain producing both 1,3-PDO and ethanol from crude glycerol has been published (Rossi et al. 2012). In order to reach high 1,3-PDO titers, the concentration of the second product, ethanol will also increase and possibly inhibit the organism. The fermentation by MNO6 only leads to small amounts of ethanol but high concentrations of butanol, which is even more toxic than ethanol. However, as butanol can be removed simultaneously by gas-stripping, it is possible to achieve high 1,3-PDO titers.

In this study, we have demonstrated that our mutant strain of $C$. pasteurianum can tolerate high concentrations of crude glycerol, has a high glycerol utilization rate, and high productivity of butanol and 1,3-PDO. Based on these results and on the results on non-treated crude glycerol, we consider MNO6 a more robust and more efficient strain than the wild type and, therefore, also better suited for industrial applications. 


\section{Competing interests}

The authors declare that they have no competing interests.

\section{Authors' contributions}

TØJ was main responsible for planning and performing the experiments, and drafted the manuscript. TK and MJM participated in planning and interpretation of experiments. PW participated in interpretation of experiments and finishing of the manuscript. All authors read and approved the final manuscript.

\section{Acknowledgments}

We acknowledge the financial support of the European Union Seventh Framework Program FP7 (Glyfinery).

\section{Author details}

${ }^{1}$ Section for Sustainable Biotechnology, Aalborg University, Copenhagen, A.C. Meyers Vaenge 15, DK-2450 Copenhagen SV, Denmark. ²Biogasol ApS, Lautrupvang 2A, DK-2750 Ballerup, Denmark.

\section{Received: 27 July 2012 Accepted: 30 July 2012}

Published: 17 August 2012

\section{References}

Annous BA, Blaschek HP (1991) Isolation and characterization of Clostridium acetobutylicum with enhanced amylolytic activity. Appl Environ Microbiol 57(9):2544-2548

Biebl H (1991) Glycerol fermentation of 1,3-propanediol by Clostridium butyricum Measurement of product inhibition by use of a pH-autostat. Appl Microbiol Biotechnol 35(6):701-705

Biebl H (2001) Fermentation of glycerol by Clostridium pasteurianum - batch and continuous culture studies. J Ind Microbiol \& Biotechnol 27(1):18-26

Biebl H, Menzel K, Zeng AP, Deckwer WD (1999) Microbial production of 1,3propanediol. Appl Microbiol Biotechnol 52(3):289-297

Borden JR, Papoutsakis ET (2007) Dynamics of genomic-library enrichment and identification of solvent tolerance genes for Clostridium acetobutylicum. Appl Environ Microbiol 73(9):3061-3068

Chatzifragkou A, Papanikolaou S, Dietz D, Doulgeraki Al, Nychas GJE, Zeng AP (2011) Production of 1,3-propanediol by Clostridium butyricum growing on biodiesel-derived crude glycerol through a non-sterilized fermentation process. Appl Microbiol Biotechnol 91(1):101-112

Dabrock B, Bahl H, Gottschalk G (1992) Parameters affecting solvent production by Clostridium pasteurianum. Appl Environ Microbiol 58(4):1233-1239

Demirbas A (2007) Importance of biodiesel as transportation fuel. Energy Policy 35(9):4661-4670

Dobson R, Gray V, Rumbold K (2012) Microbial utilization of crude glycerol for the production of value-added products. J Ind Microbiol Biotechnol 39(2):217-226

DuPont $^{\text {TM }}$ Sorona ${ }^{\circledR}$ (2011), , http://www2.dupont.com/Sorona_Consumer/en_US/ index.html. Accessed 12-Dec-2011

Dürre P (2008) Fermentative butanol production - Bulk chemical and biofuel. Ann N Y Acad Sci 1125:353-362

Elkanouni A, Junelles AM, Janatiidrissi R, Petitdemange H, Gay R (1989) Clostridium acetobutylicum mutants isolated for resistance to the pyruvate halogen analogs. Curr Microbiol 18(3):139-144

Ezeji TC, Qureshi N, Blaschek HP (2004) Acetone butanol ethanol (ABE) production from concentrated substrate: reduction in substrate inhibition by fed-batch technique and product inhibition by gas stripping. Appl Microbiol Biotechnol 63(6):653-658

Girbal L, Croux C, Vasconcelos I, Soucaille P (1995) Regulation of metabolic shifts in Clostridium acetobutylicum ATCC-824. FEMS Microbiol Rev 17(3):287-297

Gonzalez-Pajuelo M, Meynial-Salles I, Mendes F, Andrade JC, Vasconcelos I, Soucaille P (2005) Metabolic engineering of Clostridium acetobutylicum for the industrial production of 1,3-propanediol from glycerol. Metab Eng 7(5-6):329-336

Groot WJ, Luyben K (1986) In situ product recovery by adsorption in the butanol/ isopropanol batch fermentation. Appl Microbiol Biotechnol 25(1):29-31

Hild HM, Stuckey DC, Leak DJ (2003) Effect of nutrient limitation on product formation during continuous fermentation of xylose with Thermoanaerobacter ethanolicus JW200 Fe(7). Appl Microbiol Biotechnol 60(6):679-686
Jensen TØ, Kvist T, Mikkelsen M, Christensen P, Westermann P (2012) Fermentation of crude glycerol from biodiesel production by Clostridium pasteurianum. J Ind Microbiol Biotechnol 39(5):709-717

Johnson DT, Taconi KA (2007) The glycerin glut: Options for the value-added conversion of crude glycerol resulting from biodiesel production. Environ Prog 26(4):338-348

Lee SY, Lee DY, Kim TY (2005) Systems biotechnology for strain improvement. Trends Biotechnol 23(7):349-358

Lee SY, Park JH, Jang SH, Nielsen LK, Kim J, Jung KS (2008) Fermentative butanol production by clostridia. Biotechnol Bioeng 101(2):209-228

Lemmel SA (1985) Mutagenesis in Clostridium acetobutylicum. Biotechnol Lett 7(10):711-716

Malaviya A, Jang Y-S, Lee S (2012) Continuous butanol production with reduced byproducts formation from glycerol by a hyper producing mutant of Clostridium pasteurianum. Appl Microbiol Biotechnol 93(4):1485-1494

Nakas JP, Schaedle M, Parkinson CM, Coonley CE, Tanenbaum SW (1983) Systemdevelopment for linked-fermentation production of solvents from algal biomass. Appl Environ Microbiol 46(5):1017-1023

Pagliaro M, Ciriminna R, Kimura H, Rossi M, Della Pina C (2007) From glycerol to value-added products. Angew Chem Int Ed 46(24):4434-4440

Pyle DJ, Garcia RA, Wen ZY (2008) Producing docosahexaenoic acid (DHA)-rich algae from biodiesel-derived crude glycerol: Effects of impurities on DHA production and algal biomass composition. J Agric Food Chem 56(11):3933-3939

Qureshi N, Hughes S, Maddox IS, Cotta MA (2005) Energy-efficient recovery of butanol from model solutions and fermentation broth by adsorption. Bioprocess Biosystems Eng 27(4):215-222

Reimann A, Biebl H (1996) Production of 1,3-propanediol by Clostridium butyricum DSM 5431 and product tolerant mutants in fedbatch culture: Feeding strategy for glycerol and ammonium. Biotechnol Lett 18(7):827-832

Rossi DM, da Costa JB, de Souza EA, Peralba MDR, Ayub MAZ (2012) Bioconversion of residual glycerol from biodiesel synthesis into 1,3propanediol and ethanol by isolated bacteria from environmental consortia. Renew Energ 39(1):223-227

Syed QUA, Nadeem M, Nelofer R (2008) Enhanced butanol production by mutant strains of Clostridium acetobutylicum in molasses medium. Turk J Biochem 33(1):25-30

Taconi KA, Venkataramanan KP, Johnson DT (2009) Growth and solvent production by Clostridium pasteurianum ATCC (R) 6013 (TM) utilizing biodiesel-derived crude glycerol as the sole carbon source. Environ Prog Sustainable Energy 28(1):100-110

Venkataramanan KP, Boatman JJ, Kurniawan Y, Taconi KA, Bothun GD, Scholz C (2012) Impact of impurities in biodiesel-derived crude glycerol on the fermentation by Clostridium pasteurianum ATCC 6013. Appl Microbiol Biotechnol 93(3):1325-1335

Wilkens E, Ringel AK, Hortig D, Willke T, Vorlop KD (2012) High-level production of 1,3-propanediol from crude glycerol by Clostridium butyricum AKR102a. Appl Microbiol Biotechnol 93(3):1057-1063

Willke T, Vorlop K (2008) Biotransformation of glycerol into 1,3-propanediol. Eur J Lipid Sci Technol 110(9):831-840

Yazdani SS, Gonzalez R (2007) Anaerobic fermentation of glycerol: a path to economic viability for the biofuels industry. Curr Opin Biotechnol 18(3):213-219

Zeng A-P (1996) Pathway and kinetic analysis of 1,3-propanediol production from glycerol fermentation by Clostridium butyricum. Bioprocess Eng 14(4):169-175

Zeng A-P, Biebl H (2002) Bulk Chemicals from Biotechnology: The Case of 1,3Propanediol Production and the New Trends. Adv Biochem Eng Biotechnol 74:239-259

Zeng A-P, Ross A, Biebl H, Tag C, Gunzel B, Deckwer WD (1994) Multiple product inhibition and growth modeling of Clostridium butyricum and Klebsiella pneumoniae in glycerol fermentation. Biotechnol Bioeng 44(8):902-911

doi:10.1186/2191-0855-2-44

Cite this article as: Jensen et al:: Production of 1,3-PDO and butanol by a mutant strain of Clostridium pasteurianum with increased tolerance towards crude glycerol. AMB Express 2012 2:44. 